\title{
Gas Chromatography as an Analytical Monitoring Technique for Hydrogen Production from Spirulina maxima 2342
}

\author{
A. U. Juantorena1, E. Santoyo², 0. Lastres³, G. Hernández4, A. Bustos5, S. A. Gamboa², \\ P. J. Sebastian ${ }^{2 *}$ \\ ${ }^{1}$ Universidad Autónoma del Estado de Morelos, Cuernavaca, México \\ ${ }^{2}$ Instituto de Energías Renovables, Universidad Nacional Autónoma de México, Temixco, México \\ ${ }^{3}$ Universidad de Ciencias y Artes de Chiapas, UNICACH, Tuxtla Gutiérrez, México \\ ${ }^{4}$ Universidad Popular de la Chontlapa, Heroica Cárdenas, México \\ ${ }^{5}$ Instituto de Ciencias Físicas, Cuernavaca, México \\ Email: ${ }^{*}$ sjp@ier.unam.mx
}

Received 8 March 2016; accepted 2 May 2016; published 5 May 2016

Copyright (C) 2016 by authors and Scientific Research Publishing Inc.

This work is licensed under the Creative Commons Attribution International License (CC BY). http://creativecommons.org/licenses/by/4.0/

(c) (i) Open Access

\begin{abstract}
Hydrogen $\left(\mathrm{H}_{2}\right)$ production from experiments with Spirulina maxima 2342 is reported in this work. The performance of this photosynthetic microorganism for producing $\mathrm{H}_{2}$ was evaluated for the first time under specific experimental conditions (e.g., a biomass concentration of $0.34 \pm 0.02 \mathrm{~g}$, a light intensity of $150 \mu \mathrm{E} \cdot \mathrm{s}^{-1} \cdot \mathrm{m}^{-2}$ and reaction times of $19.3 \pm 1.2 \mathrm{~h}$ ). The performance of this photosynthetic microorganism for producing hydrogen was successfully improved by the addition of sodium dithionite (a reducing agent) as an innovative method for increasing the gas production, and as a main contribution of this work. Quantitative gas chromatography (GC) analyses of $\mathrm{H}_{2}$ to verify the production performance were successfully carried out at low concentration levels. GC analyses were performed by means of a conventional thermal conductivity detector coupled to a separation system of a Molecular Sieve column $500 \mathrm{~mm} \times 3175 \mathrm{~mm}$ (L $\times$ ID). Low detection limits were consistently obtained with the GC system used. The separation of $\mathrm{H}_{2}$ in culture samples was efficiently achieved in average retention times of $1.47 \mathrm{~min}$. The $\mathrm{H}_{2}$ produced in this process was subsequently used for power generation using a Proton Exchange Membrane Fuel Cell (PEMFC).
\end{abstract}

\section{Keywords}

Hydrogen Fuel, Biological Catalysts, Photo-Biological Production, Cyanobacteria, Fuel Cell, Solar Energy

\footnotetext{
"Corresponding author.

How to cite this paper: Juantorena, A.U., Santoyo, E., Lastres, O., Hernández, G., Bustos, A., Gamboa, S.A. and Sebastian, P.J. (2016) Gas Chromatography as an Analytical Monitoring Technique for Hydrogen Production from Spirulina maxima 2342. Green and Sustainable Chemistry, 6, 78-87. http://dx.doi.org/10.4236/gsc.2016.62007
} 


\section{Introduction}

The limited supply of fossil fuels and their strong environmental impact prompt the use of unconventional energy sources to face the future energy demand of the world [1]-[3]. In this respect, the use of hydrogen fuel is an attractive power source. Hydrogen $\left(\mathrm{H}_{2}\right)$ fuel is considered as one of the most promising energy alternatives due to its numerous advantages, which include environmental nature, production, efficiency and renewability [4].

Photo-biological production of $\mathrm{H}_{2}$ has advanced significantly in recent years, and it is on the way to becoming a mature technology as an energy vector. A variety of photosynthetic and non-photosynthetic microorganisms, including unicellular green algae, cyanobacteria, anoxygenic photosynthetic bacteria, obligate anaerobic, and nitrogen-fixing bacteria have been used for the $\mathrm{H}_{2}$ production [5]-[7]. Enzymes, production mechanisms, and the underlying biochemistry processes may vary among these systems; however, they are all promising biological catalysts for the hydrogen production [6].

Solar energy can be converted into chemical energy in the form of $\mathrm{H}_{2}$ gas by using oxygenic and anoxygenic photosynthetic microbes. Major challenges, such as inhibitory amounts of oxygen produced, during oxygenic photosynthesis, and inhibition of $\mathrm{H}_{2}$-producing nitrogenase by ammonia, are being studied in genetic engineering experiments [8], among other aspects on this research area [9] [10]. Microalgae are known as anext generation energy source due to high biomass productivity, high productivity in lipids and carbon neutrality [11], that is to say zero carbon footprints.

Cyanobacteria are photosynthetic prokaryotes that are promising "low-cost” microbial cell factories due to their simple nutritional requirements, metabolic plasticity, and availability for their genetic manipulation [12]. Cyanobacteria have been also proposed as promising microorganisms for the hydrogen production. In comparison with other traditional processes of hydrogen production (e.g., chemical, photoelectrical, among others), hydrogen production from cyanobacteria is commercially considered as a new viable technology [4].

Some species of cyanobacteria produce hydrogen in a natural way as a byproduct from either a dark anaerobic fermentation or a photosynthetic process using fixed-carbon compounds which are produced in daylight under aerobic conditions [10] [13]. Several experimental studies have been carried out for the photo-biological production of hydrogen from Spirulina as a biomass source (e.g., [14]-[17]).

On the other hand, analytical methodologies for detecting/quantifying the hydrogen production in photo- biological reactions using Spirulina maxima 2342 have been rarely reported in the literature (e.g., [14]). Most of these methodologies have used the gas chromatography (GC) with thermal conductivity detection (TCD) with non-suitable detection limits for analysing low levels of concentration (e.g., [5] [14]). Other analytical techniques for measuring hydrogen include fluorimetric techniques, GC coupled with flame ionization detection, GC coupled with a flame photometric detection, GC coupled with aniodometric titration, potentiometry with ionselective electrodes, spectrophotometry, and high-performance liquid chromatography (e.g., [18]).

In this paper, a new experimental application of the Spirulina maxima 2342 for the production of $\mathrm{H}_{2}$ is reported. The performance of this photosynthetic microorganism for producing $\mathrm{H}_{2}$ was successfully improved under some particular experimental conditions. The main objective of this work is to report quantitatively the production of hydrogen from the use of Spirulina maxima 2342 by using controlled experimental conditions of the following key processes: biomass production, anaerobiosis/dark process and the detection/quantification of hydrogenproduction at low concentrations by GC coupled with TCD. Details of the experimental work methodology and the results are outlined.

\section{Experimental Details}

The experimental work methodology used for the production of hydrogen from Spirulina maxima 2342 microorganisms is schematically shown in Figure 1. Such a methodology includes the following crucial experimental stages: a biomass production through the systematic culture of photosynthetic microorganisms; an anaerobiosis/ dark process controlled with sodium dithionite addition; and a detection/quantification of hydrogen production at low concentrations by TCD-GC.

\subsection{Biomass Production}

The biomass production with the systematic culture of photosynthetic microorganisms used Spirulina maxima 2342 (UTEX collection). These microorganisms was cultivated under illumination conditions of $156 \mathrm{~W}$, which 


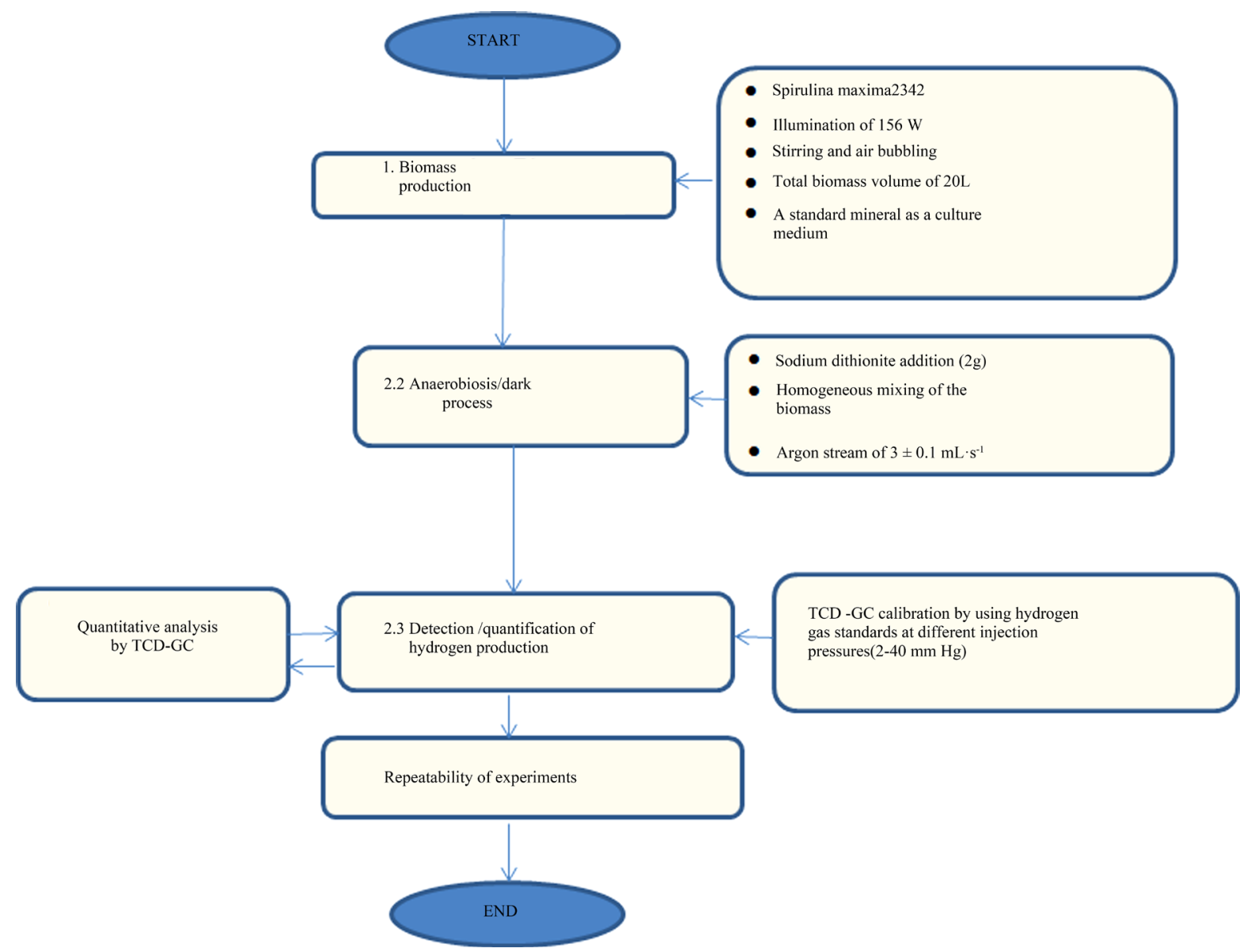

Figure 1. Experimental methodology used for the production of hydrogen from Spirulina maxima 2342.

were provided by 4 fluorescent lamps of $39 \mathrm{~W}$. Stirring and air bubbling conditions were also used for obtaining a total biomass volume of 20 L. A standard mineral was used as a culture medium [19]. In addition, general features or composition of Spirulina maxima 2342 is determined.

Duplicate experiments at a laboratory temperature of $25^{\circ} \mathrm{C}$ were systematically carried out by using homemade glass biomass photobioreactors (Figure 2). After 25 days of incubation, a sample volume of biomass (250 $\mathrm{mL}$ ) was collected and concentrated by a filtration process. The quality of the photosynthetic biomass samples was monitored in terms of the microorganism-biomass quality index parameters: dry-weight content of biomass and Chlorophyll $a$ concentration, according to the methodology suggested by Arnon in 1949 [20]. Digital photographs of Spirulina maxima (UTEX-2342) cells are shown in Figure 2. Such images were recorded with a digital camera (NIKON) coupled to an optical microscope HITACHI KP-D50 and a scanning electron microscope (SEM).

Physicochemical properties of the photosynthetic biomass samples were also measured. The optical density (OD) of the biomass samples were measured by spectrometry using a DU 650 Beckman spectrophotometer calibrated at a wavelength of $750 \mathrm{~nm}$, whereas the $\mathrm{pH}$ measurements were performed by a 430 Corning pH-meter. Dry weight of the biomass samples was determined after filtration through a filter paper Whatman (diameter 47 $\mathrm{mm}$ ). The remaining residue collected on the filter paper was also dried in an oven at $75^{\circ} \mathrm{C}$ for $24 \mathrm{~h}$.

Chlorophyll-a [Chla] concentration (in mg) of biomass was spectrophotometrically determined by measuring the absorbance responses at $645 \mathrm{~nm}$ (A645) and $663 \mathrm{~nm}$ (A663) using $15 \mathrm{~mL}$ of methanol (as solvent) and 10 $\mathrm{mL}$ of sample (as aqueous solution). Chlorophyll- $a$ [Chla] concentration (in $\mathrm{mg}$ ) was subsequently calculated by means of the equation suggested by Arnon in 1949 [20]:

$$
[\mathrm{Cha}]=12.7(\mathrm{OD} \text { A663) }-2.69(\mathrm{OD} \text { A645) }
$$




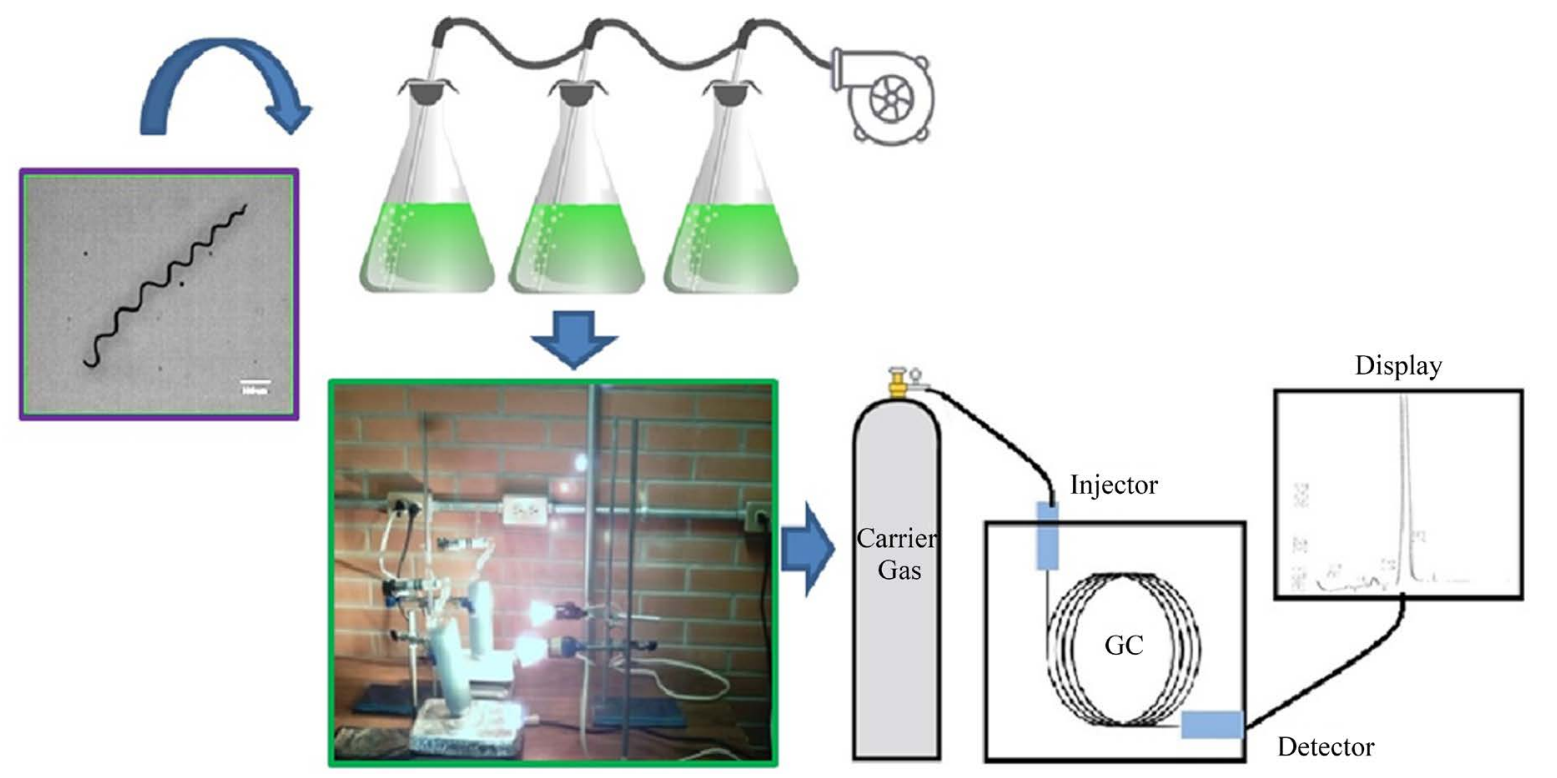

Figure 2. Hydrogen production from Spirulina maxima 2342: schematic process.

\subsection{Anaerobiosis/Dark Process}

According to the work methodology described in Figure 1, the hydrogen production from Spirulina maxima 2342 was conducted by a mixed process of anaerobiosis and darkness. The experiment was carried out in two identical home-made glass biomass photobioreactors at a laboratory temperature of $25^{\circ} \mathrm{C}$. The biomass photobioreactors have a sample volume of $300 \mathrm{~mL}$, which were equipped with a vacuum/pressure Teflon $^{\circledR}$ stopcock [17] both for facilitating the sample collection and to preserve the sample without air contamination for its later chemical analysis. These photobioreactors were initially set under vacuum conditions for filling the biomass samples. A volume of $250 \mathrm{~mL}$ of biomass culture was added to each photobioreactor, and $2 \mathrm{~g}$ of sodium dithionite were finally added to promote the oxygen removal process, which inhibits the hydrogenase enzyme that affect the production of hydrogen.

Sodium dithionite (also known as sodium hydrosulfite, $\mathrm{Na}_{2} \mathrm{~S}_{2} \mathrm{O}_{4}$ ) is a white crystalline powder with a weak sulphurous odour. It can be obtained from sodium bisulphite through the reaction: $2 \mathrm{NaHSO}_{3}+\mathrm{Zn} \rightarrow \mathrm{Na}_{2} \mathrm{~S}_{2} \mathrm{O}_{4}+$ $\mathrm{Zn}(\mathrm{OH})_{2} \cdot \mathrm{Na}_{2} \mathrm{~S}_{2} \mathrm{O}_{4}$ is usually recommended as reducing agent for redox and solubility reactions [21] [22].

To ensure a homogeneous mixing of the biomass sample, a stirring process for 5 min was additionally performed. The photobioreactors were then placed into a dark anaerobic process by passing an argon gas stream (industrial grade) of $3 \pm 0.1 \mathrm{~mL} \cdot \mathrm{s}^{-1}$ for $1 \mathrm{~h}$ to increase the removal of dissolved oxygen.

After the anaerobiosis/dark process, a vacuum process was again applied to the photobioreactor sample during 5 min for trying to complete the oxygen removal, which was difficult to achieve due to the dynamics of the photosynthesis process.

\subsection{Detection/Quantification of Hydrogen Production}

To have a photoproduction of hydrogen (at low concentrations by gas chromatography coupled with TCD), with high performance, a stirring-illumination process with a $100 \mathrm{~W}$ lamp, a light intensity of $150 \mu \mathrm{E} \cdot \mathrm{s}^{-1} \cdot \mathrm{m}^{-2}$, and a reaction time of $19.3 \pm 1.2 \mathrm{~h}$ were needed. A picture showing some details of the experimental system used for the photoproduction of hydrogen gas is presented in Figure 2.

To have a statistical reproducibility of the hydrogen photoproduction process, three experimental runs with 2 replicates for each one were carried out. To verify the hydrogen gas photoproduction, the biomass reactors were connected to a gas chromatograph (GC) system equipped with a thermal conductivity detector (TCD) for a reliable detection and quantification of the hydrogen gas produced with the biomass samples. The GC system was previously calibrated with hydrogen standards of high purity. Calibration curves were specifically prepared, which were subsequently used to quantify the amount of hydrogen produced with the experimental system. 


\section{Results and Discussion}

The performance of the Spirulina maxima 2342 as aphotosynthetic microorganism for producing hydrogen was successfully improved by the addition of sodium dithionite (a reducing agent) as an innovative method to increase the gas production. Such an improvement was achieved by means of the following experimental stages: biomass production: the systematic culture of photosynthetic microorganisms where an oxygenic photosynthesis to $\mathrm{CO}_{2}$ fixation in the photobioreactor was promoted; anaerobiosis/dark process, where the microorganisms are exposed to a synthesis of hydrogenase enzyme (to start the hydrogen production from carbon hydrates stored under dark conditions), followed by an illumination process to complete the $\mathrm{H}_{2}$ production; and the detection/ quantification of hydrogenproduction at low concentrations by TCD-GC.

\subsection{Biomass Production: The Systematic Culture of Photosynthetic Microorganisms}

In this stage, the production of the photosynthetic biomass of Spirulina maxima 2342 as a fundamental raw material of the process was obtained. After applying the photosynthetic experimental conditions (previously described), the Spirulina maxima 2342 biomass samples were efficiently and systematically produced. According to the microorganism-biomass quality index measurements, the Spirulina maxima 2342 samples presented the following average properties: a dried biomass of $0.34 \pm 0.02 \mathrm{~g}$; a pH of $10.19 \pm 0.05$; and Chlorophyll $a$ (mg) and Chlorophyll $a$ /biomass concentrations of $2.5 \pm 0.3 \mathrm{mg}$ and $7 \pm 1 \mathrm{mg} \cdot \mathrm{g}^{-1}$, respectively. According to the quality index parameters reported by Oswald in 1977 [23], the Chlorophyll a/biomass concentrations measured in the samples falls within the expected values for such photosynthetic microorganisms (between 3 and 10 $\left.\mathrm{mg} \cdot \mathrm{g}^{-1}\right)$.

\subsection{Anaerobiosis/Dark Process}

In this stage, it was found that the photosynthetic microorganisms simultaneously co-produced hydrogen and oxygen gases in a very similar way over the experimental time. This co-production of oxygen affected the amount of hydrogen produced in the photobioreactor because it inhibited the performance of the hydrogenase enzyme [24]. To remove the oxygen produced by the microorganisms, and therefore to solve this co-production problem, sodium dithionite were added as reducing agent. This optimum dose of sodium dithionite enabled the oxygen removal from the anaerobiosis/dark process to be successfully achieved.

\subsection{Detection/Quantification of Hydrogen}

Detection/quantification of hydrogen at low concentrations by TCD-GC system used in this experimental study is shown in Figure 2. This analytical system was calibrated for measuring the hydrogen concentrations with precision and accuracy. Praxair ${ }^{\circledR}$ gas standards of high purity (99.9999\%) were used for the calibration of the TCD-GC. A standard gas mixture containing 5\% He, 10\% $\mathrm{H}_{2}, 10 \% \mathrm{Ar}, 45 \% \mathrm{~N}_{2}$ and $30 \% \mathrm{CH}_{4}$ was used. The operating conditions of the GC system are summarized in Table 1.

Typical chromatograms obtained from the injection of the hydrogen standards are shown in Figures 3(a)-(e). A similar separation pattern was consistently achieved during the hydrogen analysis of samples obtained from the three production experiments. From these chromatograms, it can be observed that the hydrogen gas was acceptably eluted from the rest of the gases with average retention times of $1.47 \mathrm{~min}$ and the same are increasing in size in increasing the injection pressure observed.

Gas standards at total pressures of 2, 5, 10, 20 and $40 \mathrm{~mm}$ Hg were injected into the TCD-GC with some replicates $(n=3)$. According to the composition of the standard mixture, five calibration points with partial pressures of hydrogen $(0.2,0.5,1.0,2.0$ and $4.0 \mathrm{~mm} \mathrm{Hg}$ ) were processed together with their respective detection responses (or peak areas). Calibration curves between TCD responses (in peak area units) and partial pressure data were then prepared for the analysis of the gas samples obtained from the three production experiments (Figures 4(a)-(c)). The linear regression equations are also included in such figures.

Table 2 summarizes both the values of the independent (partial pressure measurements) and dependent (TCD responses) variables of the TCD-GC analyses, together with the precision data. The calibration curves were then used to quantify the hydrogen generated by the photosynthetic microorganisms from the peak areas obtained from the gas samples. These partial pressure values, molar fractions and concentration units were calculated by 
Table 1. Operational parameters of the TCD-GC system.

\begin{tabular}{cc}
\hline Chromatography Column & Mol Sieve GC column $(5 \mathrm{~m} \times 3.175 \mathrm{~mm})$ \\
\hline Carrier gas & Argon Ar Chromatographic grade: $99.998 \%$ purity (INFRA) \\
Carrier gas flow & $30 \mathrm{~mL} \cdot \mathrm{min}^{-1}$ \\
Detector temperature & $110^{\circ} \mathrm{C}$ \\
Filament temperature & $140^{\circ} \mathrm{C}$ \\
Column temperature & $60^{\circ} \mathrm{C}$ \\
\hline
\end{tabular}

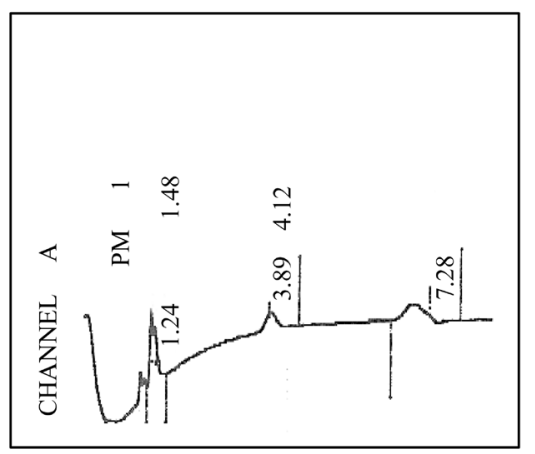

(a)

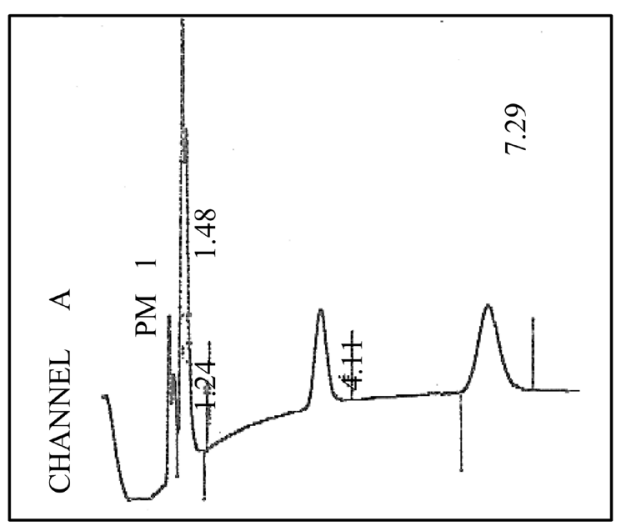

(c)

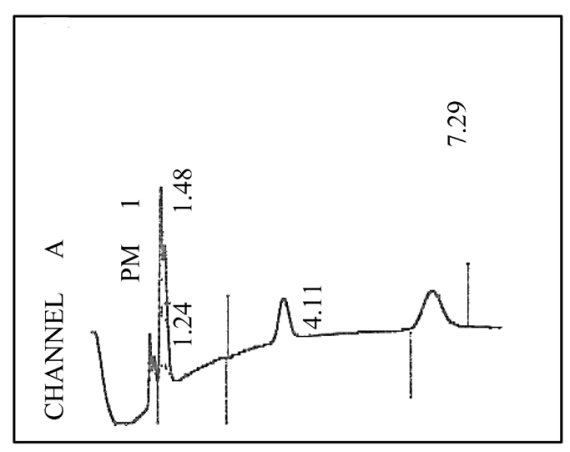

(b)

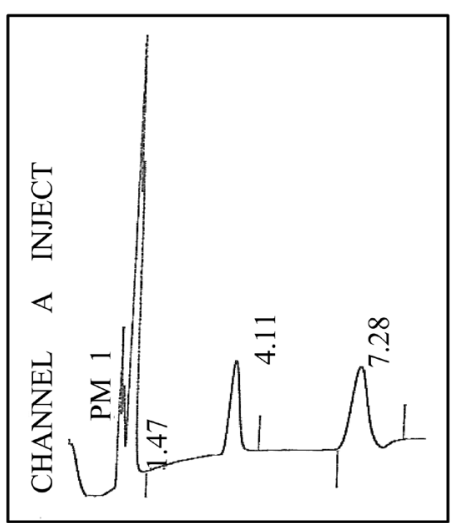

(d)

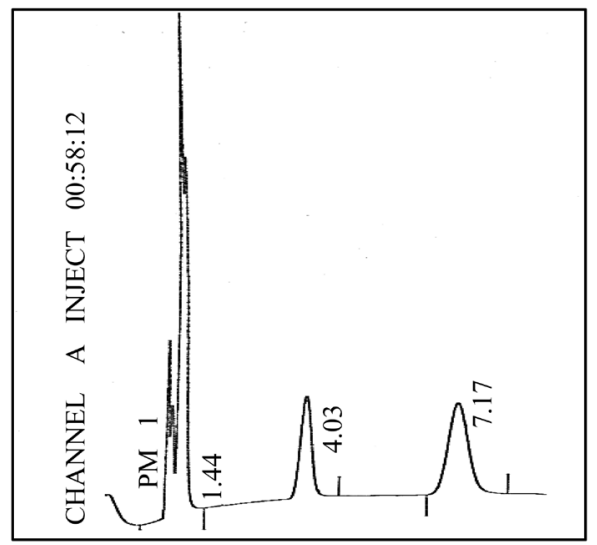

(e)

Figure 3. Typical gas chromatograms obtained from the experiment No. 3 at different partial pressures injections of $\mathrm{H}_{2}: 2 \mathrm{~mm} \mathrm{Hg} \mathrm{(a);} 5 \mathrm{~mm} \mathrm{Hg} \mathrm{(b);} 10 \mathrm{~mm} \mathrm{Hg} \mathrm{(c);} 20 \mathrm{~mm}$ $\mathrm{Hg}$ (d); 40 mm Hg (e). 


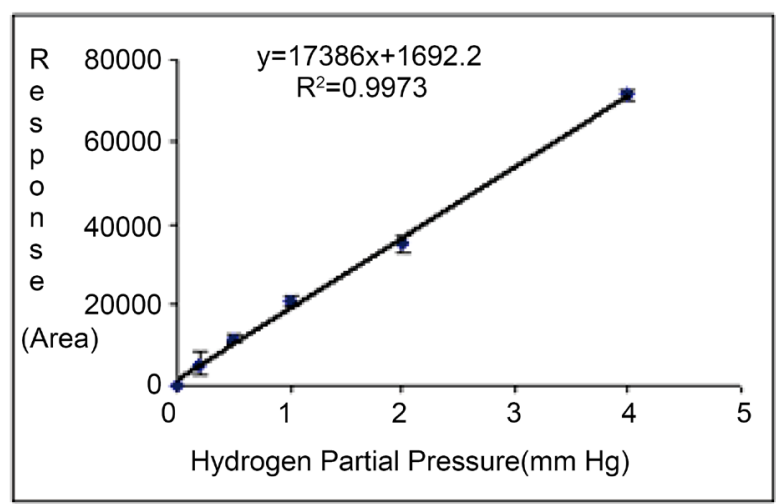

(a)

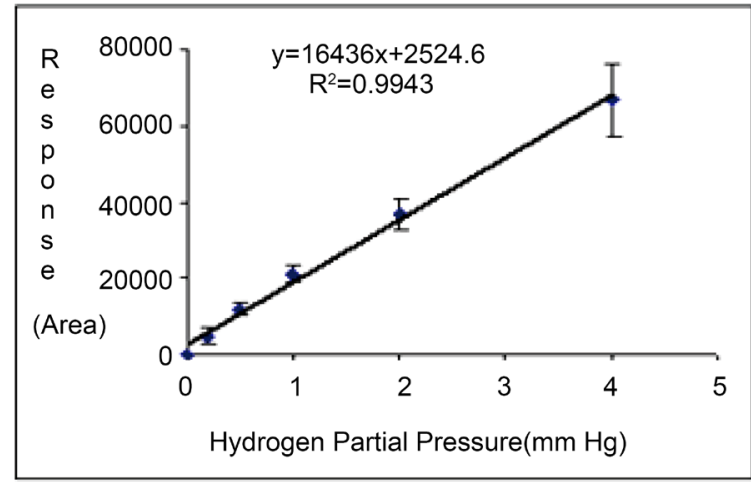

(b)

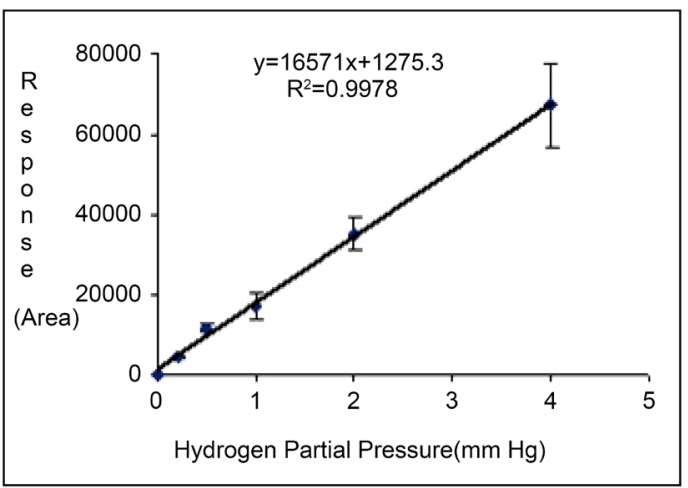

(c)

Figure 4. Replicated calibration curves of hydrogen obtained from the use of the standard gas mixture at several injection partial pressures ((a) Experiment 1; (b) Experiment 2; and (c) Experiment 3).

Table 2. Results of the chromatographic analyses of $\mathrm{H}_{2}$ obtained for three injections of the standard gas mixture.

\begin{tabular}{ccccc}
\hline $\begin{array}{c}\text { Total injection pressure } \\
(\mathrm{mm} \mathrm{Hg})\end{array}$ & $\begin{array}{c}\text { Partial injection } \\
\text { pressure }(\mathrm{mm} \mathrm{Hg})\end{array}$ & $\begin{array}{c}\text { Retention time } \\
(\mathrm{min})\end{array}$ & $\begin{array}{c}\text { Peak area } \\
\text { (counts) }\end{array}$ & $\begin{array}{c}\text { Precision error } \\
(\%)\end{array}$ \\
\hline 2 & 0.2 & $1.48 \pm 0.01$ & $4827 \pm 469$ & 9.7 \\
5 & 0.5 & $1.48 \pm 0.01$ & $11,766 \pm 236$ & 2.0 \\
10 & 1.0 & $1.48 \pm 0.01$ & $17,079 \pm 2177$ & 12.7 \\
20 & 2.0 & $1.47 \pm 0.00$ & $35,657 \pm 1133$ & 3.2 \\
40 & 4.0 & $1.44 \pm 0.01$ & $68,533 \pm 2597$ & 3.8 \\
\hline
\end{tabular}

using the equation of the ideal gas law. This quantitative methodology was valid due to the low work pressures, restricted condition for such a general equation. Hydrogen detections in culture samples Spirulina maxima 2342 were for total injection pressures with minimum of $91 \mathrm{~mm} \mathrm{Hg}$ and up to $367 \mathrm{~mm} \mathrm{Hg}$.

Example of a typical chromatogram obtained from the hydrogen production experiments is shown in Figure 2. Hydrogen detection is confirmed by means of the peak observed at a retention time of 1.44 min. The typical chromatogram of hydrogen detection is obtained during the injection of gas samples at an injection pressure of 258 mm Hg (Experiment 3).

A summary of the experimental results obtained at $\mathrm{H}_{2}$ injection pressures in the standard gas between 0 and 40 $\mathrm{mm}$ of $\mathrm{Hg}$ is shown in Table 3. It was obtained a ratio of $21 \times 10^{-10} \mathrm{~mol} \mathrm{of} \mathrm{H}_{2} \mathrm{~h}^{-1} / 2.5 \mathrm{mg}$ of Chlorophyll $a$ in our experiments with biomass of Spirulina maxima 2342, in the experimental conditions established and in two phases of experimentation. The first one, production of photosynthetic biomass and then inducing the $\mathrm{H}_{2}$ production by anaerobiosis/darkness and the second the hydrogen photoproduction with a reaction time of $19.3 \pm$ $1.2 \mathrm{~h}$. 
Table 3. Final results after the application of the methodology.

\begin{tabular}{rcccccc}
\hline $\begin{array}{c}\mathrm{P}_{\text {total }} \\
\left(\mathrm{N} \cdot \mathrm{m}^{-2}\right)\end{array}$ & $\begin{array}{c}\mathrm{V}_{\text {total }} \\
\left(\mathrm{m}^{3}\right)\end{array}$ & $\begin{array}{c}\mathrm{P}_{\mathrm{H} 2} \\
\left(\mathrm{~N} \cdot \mathrm{m}^{-2}\right)\end{array}$ & $\begin{array}{c}\mathrm{V}_{\mathrm{H} 2} \\
\left(\mathrm{~m}^{3}\right)\end{array}$ & $\mathrm{X}_{\mathrm{i}}$ & $\begin{array}{c}\mathrm{n}_{\mathrm{H} 2} \\
(\mathrm{~mol})\end{array}$ & $\begin{array}{c}\mathrm{n}_{\mathrm{H} 2} \\
\left(\mathrm{~mol} \cdot \mathrm{h}^{-1}\right)\end{array}$ \\
\hline 87017.91 & $4.4 \times 10^{-5}$ & 22.7 & $6.6 \times 10^{-8}$ & 0.0015 & $6.1 \times 10^{-10}$ & $21 \times 10^{-10}$ \\
\hline
\end{tabular}

This method of obtaining photosynthetic hydrogen in 2 phases has been demonstrated in this work and has also been reported by other authors. For example, Nath and Das in 2004 [25], confirmed that the integration of a fermentation process with photosynthesis is a way to improve the hydrogen productivity. Skizim, et al. in 2012 [26] used Cyanothece sp. Miami BG 043511 cultivated in ASP2 medium at $30^{\circ} \mathrm{C}$ without inorganic nitrogen combining $12 \mathrm{~h}$ light, $12 \mathrm{~h}$ darkness and with a light intensity of $30 \mu \mathrm{E} \mathrm{s} \cdot \mathrm{m}^{-2}$. The maximum sustained rate of hydrogen production in Cyanothece sp. Miami BG 043511 in 2.5 h reported by Skizim et al. in 2012 [26] was $16.4 \mu \mathrm{mol}$ of $\mathrm{H}_{2}$ per g dry weight ${ }^{-1} \cdot \mathrm{h}^{-1}\left(15.8 \mathrm{~mL}\right.$ of $\left.\mathrm{H}_{2} \operatorname{liter}^{-1} \cdot \mathrm{h}^{-1}\right)$. Rocheleau in 2000 [27] obtained 0.11 $\mu \mathrm{mol} \cdot \mathrm{g}^{-1}$ with Spirulinaplatensis darkness/anaerobiosis fermentation in laboratory work, confirming that Cyanobacteria produces hydrogen by dark fermentations, but not in the light phase.

Environmental and nutritional conditions that optimize the yield of hydrogen $\left(\mathrm{H}_{2}\right)$ from water using a twostep photosynthesis/fermentation (P/F) process was reported for the hypercarbonate-requiring cyanobacterium “Arthrospira maxima” by Ananyev et al. in 2008 [28], in relation to fermentative $\mathrm{H}_{2}$ production by bacteria. Anaerobic $\mathrm{H}_{2}$ production in the dark from whole cells catalyzed by a bidirectional [NiFe] hydrogenase is demonstrated to occur in two temporal phases involving two distinct metabolic processes that are linked to prior light-dependent production of NADPH (photosynthetic) and dark/anaerobic production of NADH (fermentative), respectively.

Borodin et al. in 2002 [29] reported that higher rates for the same strain grown in a photobioreactor where actively growing cells were held at a chlorophyll concentration of $4 \mu \mathrm{g} / \mathrm{mL}\left(6.3 \mathrm{~mL} \mathrm{of} \mathrm{H}_{2} \operatorname{liter}^{-1} \cdot \mathrm{h}^{-1}\right.$ or $70 \mu \mathrm{mol}$ of $\mathrm{H}_{2} \mathrm{mg}$ of $\mathrm{Chl}^{-1} \cdot \mathrm{h}^{-1}$ ). In Cyanothece sp. ATCC 51142, when supplemented with $50 \mathrm{mM}$ glycerol extremely high rates of 373 and $465 \mu \mathrm{mol}$ of $\mathrm{H}_{2}$ per $\mathrm{mg}$ of $\mathrm{Chl}^{-1} \cdot \mathrm{h}^{-1}$ have been reported [30].

Dutta et al. in 2005 [31] reported $167.6 \mu \mathrm{mol}$ of $\mathrm{H}_{2}$ per $\mathrm{mg}$ of $\mathrm{Chl}^{-1} \cdot \mathrm{h}^{-1}$ for Anabaena variabilis sp. ATCC 29413 PK84 mutant, that they are significantly higher than the maximum rates published to date for both heterocystous and diazotrophs. The hydrogen production in Arthrospira maxima via bidirectional hydrogenase was only $3.1 \mu \mathrm{mol}$ of $\mathrm{H}_{2}$ per mg of $\mathrm{Chl}^{-1} \cdot \mathrm{h}^{-1}$ reported by Carrieri et al. in 2008 [32].

\section{Conclusion}

It demonstrated the $\mathrm{H}_{2}$ production from Spirulina maxima 2342. The production involves two different metabolic processes which are linked: the light-dependent production(photosynthetic) and the anaerobiosis/darkness (fermentative) and the hydrogen gas was detected under established experimental conditions in a gas chromatograph with TCD obtaining $21 \times 10^{-10} \mathrm{~mol}$ of $\mathrm{H}_{2} \cdot \mathrm{h}^{-1} / 2.5 \mathrm{mg}$ Chlorophyll $a$ and with a reaction time of $19.3 \pm 1.2 \mathrm{~h}$.

\section{Acknowledgements}

The authors wish to thank Dr. Portugal, E., Sánchez, D. and Betancourt, V. of the Electrical Research Institute, Cuernavaca, Morelos, Mexico, for the technical help. This work was carried out with financial support through the project CONACYT INF224765.

\section{References}

[1] Darmstadter, J. (2010) The Prospective Role of Unconventional Liquid Fuels Resources for the Future. http://nepinstitute.org/get/RFF_Reports/Background-Papers/RFF-NEPI-Darmstadter-AltLiquidFuels.pdf

[2] World Energy Insight (WEI) (2012) World Energy Council. Istanbul http://www.worldenergy.org/wp-content/uploads/2012/10/PUB_World-Energy-Insight_2012_WEC.pdf

[3] Browne, J. (2013) Proposal-The Energy Crisis and Climate. Global Economic Symposium Change. http://www.global-economic-symposium.org/knowledgebase/the-global-environment/the-energy-crisis-and-climate-ch ange/proposals/the-energy-crisis-and-climate-change

[4] Min, H. and Sherman, L. (2010) Hydrogen Production by the Unicellular, Diazotrophic Cyanobacterium Cyanothece sp. Strain ATCC 51142 under Conditions of Continuous Light. Applied and Environmental Microbiology, 13, 
4293-4301.

http://dx.doi.org/10.1128/AEM.00146-10

[5] Hemschemeier, A., Melis, A. and Happe, T. (2009) Analytical Approaches to Photobiological Hydrogen Production in Unicellular Green Algae. Photosynthesis Research, 102, 523-540. http://dx.doi.org/10.1007/s11120-009-9415-5

[6] Eroglu, E. and Melis, A. (2011) Photobiological Hydrogen Production: Recent Advances and State of the Art. Bioresource Technology, 102, 8403-8413. http://dx.doi.org/10.1016/j.biortech.2011.03.026

[7] Skizim, N.J., Ananyev, G.M., Krishnan, A. and. Dismukes, G. (2012) Metabolic Pathways for Photobiological Hydrogen Production by Nitrogenase- and Hydrogenase-Containing Unicellular Cyanobacteria Cyanothece. The Journal of Biological Chemistry, 4, 2777-2786. http://dx.doi.org/10.1074/jbc.M111.302125

[8] McKinlay, J.B. and Harwood, C.S. (2010) Photobiological Production of Hydrogen Gas as a Biofuel. Current Opinion in Biotechnology, 3, 244-251. http://dx.doi.org/10.1016/j.copbio.2010.02.012

[9] McNeely, K., Xu, Y., Bennette, N., Bryant, D. and Dismukes, G. (2010) Redirecting Reductant Flux into Hydrogen Production via Metabolic Engineering of Fermentative Carbon Metabolism in a Cyanobacterium. Applied and Environmental Microbiology, 15, 5032-5038. http://dx.doi.org/10.1128/AEM.00862-10

[10] McNeely, K., Xu, Y., Ananyev, G., Bennette, N., Bryant, D. and Dismukes, G. (2011) Synechococcus sp. Strain PCC 7002 nifJ Mutant Lacking Pyruvate: Ferredoxin Oxidoreductase. Applied and Environmental Microbiology, 7, 24352444. http://dx.doi.org/10.1128/AEM.02792-10

[11] Chi, Y., Chen, F. and Takiguchi, Y. (2015) Effect of Nitrogen Source on Biomass and Lipid Production of a Marine Microalga, Nannochloropsis oceanica IMET1. Green and Sustainable Chemistry, 5, 101-106. http://dx.doi.org/10.4236/gsc.2015.52013

[12] Pinto, F., Van Elburg, K., Pacheco, C., Lopo, M., Noirel, A., Montagud, A., Urchuegura, F., Wright, P. and Tamagnini, P. (2012) Construction of a Chassis for Hydrogen Production: Physiological and Molecular Characterization of a Synechocystis sp. PCC 6803 Mutant Lacking a Functional Bidirectional Hydrogenase. Microbiology, 158, 448-464. http://dx.doi.org/10.1099/mic.0.052282-0

[13] Carrieri, D., Ananyev, G., Lenz, O. and Donald, A. (2011) Contribution of a Sodium Ion Gradient to Energy Conservation during Fermentation in the Cyanobacterium Arthrospira (Spirulina) maxima CS-328. Applied and Environmental Microbiology, 20, 7185-7194. http://dx.doi.org/10.1128/AEM.00612-11

[14] Juantorena, A.U. (2007) Hydrogen Production from Fhotosynthetic Microorganisms for Use in PEM Fuel Cells Engineering. PhD Thesis, CIE-UNAM, Mexico.

[15] Juantorena, A.U., Sebastian, P.J., Santoyo, E., Gamboa, S., Lastres, O., Sánchez, D., Bustos, A. and Eapen, D. (2007) Hydrogen Production Employing Spirulina maxima 2342: A Chemical Analysis. International Journal of Hydrogen Energy, 32, 3133-3136. http://dx.doi.org/10.1016/j.ijhydene.2006.02.033

[16] Carrieri, D. (2009) Physiological Control of Photosynthesis and Fermentation in the Cyanobacterium Arthrospira (Spirulina) maxima CS-328 for Biofuel Production. PhD Thesis, Princeton University, Princeton.

[17] Juantorena, A.U., Lastres, O., Hernández, G., Bustos, A., Sebastian, P.J. and Eapen, D. (2012) Hydrogen Production by Microorganisms and Its Application in a PEMFC. International Journal of Energy Research, 26, 902-910. http://dx.doi.org/10.1002/er.1844

[18] Sulu, M. (2009) The Process Intensification of Biological Hydrogen Production by Escherichia coli HD701. PhD Thesis, The University of Birmingham, Birmingham.

[19] Ogawa, T. and Terui, G. (1972) Growth Kinetics of Spirulina platensis in Autotrophic and Mixotrophic Cultures. In: Terui, G., Ed., Proceedings of IV IFS: Fermentation Technology Today, Society of Fermentation Technology, Osaka, 543-549.

[20] Arnon, D. (1949) Copper Enzymes in Isolated Chloroplasts. Polyphenoloxidase in Beta vulgaris. Plant Physiology, 24, 1-15. http://dx.doi.org/10.1104/pp.24.1.1

[21] QuimNet (2008). http://www.quiminet.com/articulos/usos-y-aplicaciones-del-hidrosulfito-de-sodio-30261.htm

[22] Ágreda, F., Arcia, E., Jované, S., Pino, E., Tufiño, E. and Lagrutta, F. (2004) Frecuencia de Portadores del Alelo S en la Población de 15-49 años de Portobelo. Panamá. Revista Médico Científica, 17, 20.

[23] Oswald, W. (1977) Handbook of Microbiology. CRC Press, Cleveland.

[24] Wünschiers, R. and Lindblad, P. (2002) Hydrogen in Education-A Biological Approach. International Journal of Hydrogen Energy, 27, 1131-1140. http://dx.doi.org/10.1016/S0360-3199(02)00098-8

[25] Nath, K. and Das, D. (2004) Improvement of Fermentative Hydrogen Production: Various Approaches. Applied Microbiology and Biotechnology, 65, 520-529. http://dx.doi.org/10.1007/s00253-004-1644-0

[26] Skizim, N., Ananyev, G., Krishnan, A. and Dismukes, G. (2012) Metabolic Pathways for Photobiological Hydrogen Production by Nitrogenase and Hydrogenase-Containing Unicellular Cyanobacteria Cyanothece. Journal of Biological 
Chemistry, 287, 2777-2786. http://dx.doi.org/10.1074/jbc.M111.302125

[27] Rocheleau, R. (2000) Biohydrogen Production. Report to the US Department of Energy Hydrogen Program, Hawaii Natural Energy Institute, University of Hawaii, Honolulu.

[28] Ananyev, G., Carrieri, D. and Dismukes, G. (2008) Optimization of Metabolic Capacity and Flux through Environmental Cues to Maximize Hydrogen Production by the Cyanobacterium "Arthrospira (Spirulina) maxima”. Applied and Environmental Microbiology, 19, 6102-6113. http://dx.doi.org/10.1128/AEM.01078-08

[29] Borodin, V., Rao, K. and Hall, D. (2002) Manifestation of Behavioral and Physiological Functions of Synechococcus sp. Miami BG 043511 in a Photobioreactor. Marine Biology, 140, 455-463. http://dx.doi.org/10.1007/s00227-001-0721-5

[30] Bandyopadhyay, A., Stöckel, J., Min, H., Sherman, L. and Pakrasi, H. (2010) High Rates of Photobiological $\mathrm{H}_{2}$ Production by a Cyanobacterium under Aerobic Conditions. Nature Communications, 1, 139. http://dx.doi.org/10.1038/ncomms1139

[31] Dutta, D., De, D., Chaudhuri, S. and Bhattacharya, S. (2005) Hydrogen Production by Cyanobacteria. Microbial Cell Factories, 4, 36. http://dx.doi.org/10.1186/1475-2859-4-36

[32] Carrieri, D., Ananyev, G., Costas, A., Bryant, D. and Dismukes, G. (2008) Renewable Hydrogen Production by Cyanobacteria: Nickel Requirements for Optimal Hydrogenase Activity. International Journal of Hydrogen Energy, 33, 2014-2022. http://dx.doi.org/10.1016/j.ijhydene.2008.02.022

\section{Nomenclature}

$\mathrm{n}_{\mathrm{H} 2}$ : mole number of hydrogen

$\mathrm{P}_{\mathrm{H} 2}$ : hydrogen partial pressure $\left[\mathrm{N} \cdot \mathrm{m}^{-2}\right]$

$\mathrm{V}_{\mathrm{H} 2}$ : hydrogenpartial volume $\left[\mathrm{m}^{3}\right]$

$\mathrm{T}$ : absolute temperature $[\mathrm{K}]$

R: universal gas constant $\left[\mathrm{N} \cdot \mathrm{m} \cdot \mathrm{mol}^{-1} \cdot \mathrm{K}^{-1}\right]$

$\mathrm{X}_{\mathrm{i}}$ : gas molar fraction

$\mathrm{P}_{\text {total }}$ : total pressure of the gas mixture $\left[\mathrm{N} \cdot \mathrm{m}^{-2}\right]$

$\mathrm{V}_{\text {total }}$ : total volume of the gas mixture $\left[\mathrm{m}^{3}\right]$ 